\title{
Zinc status of northern Tasmanian adults
}

\author{
Jeffrey M. Beckett* and Madeleine J. Ball \\ School of Health Sciences, University of Tasmania, Launceston, Australia \\ (Received 25 June 2014 - Final revision received 21 January 2015 - Accepted 17 February 2015) \\ Journal of Nutritional Science (2015), vol. 4, e15, page 1 of 7
}

doi:10.1017/jns.2015.12

Abstract

Information regarding $\mathrm{Zn}$ status in the Australian population is very limited. Mild deficiencies in $\mathrm{Zn}$ have been associated with CVD, impaired immune function and poor healing. A cross-sectional study of 497 northern Tasmanian adults (24-82 years of age) was conducted to assess $\mathrm{Zn}$ status. Dietary intakes were assessed by FFQ and serum concentrations of Zn were evaluated using International Zinc Nutrition Consultative Group methodology. Mean $\mathrm{Zn}$ intakes were 12.6 (sD 4.4 ) $\mathrm{mg} / \mathrm{d}$ for men and 10.9 (sD 3.6) $\mathrm{mg} / \mathrm{d}$ for women. It was found that $52 \%$ of men but only $9 \%$ of women consumed less than the Australia/New Zealand estimated average requirement for Zn. Mean serum Zn was 13.0 (sD 2.4) $\mu \mathrm{mol} / 1$ in men and 13.0 (SD 2.5) $\mu \mathrm{mol} / 1$ in women. Overall, $15 \%$ of men and $7 \%$ of women had low serum Zn levels. Furthermore, low serum Zn was observed in $18 \%$ of men 50 years or older and $30 \%$ of men 70 years or older. The present results suggest that mild Zn deficiency may be prevalent in older Tasmanian adults, particularly men; and due to the importance of $\mathrm{Zn}$ in many areas of health, this could be of public health concern.

Key words: Zinc status: Population studies: Australia

Conservative estimates place approximately $20 \%$ of the world's population at risk of Zn deficiency ${ }^{(1)}$. While it is a significant cause of morbidity in many developing countries, in developed countries information regarding the prevalence of $\mathrm{Zn}$ deficiency is more limited.

There is a paucity of data relating to the $\mathrm{Zn}$ status of Australians. As noted in a recent review of the literature concerning $\mathrm{Zn}$ status in Australia and New Zealand ${ }^{(2)}$, even in population groups considered 'at risk' there are few studies that have assessed Zn status. Published studies are generally limited by size, have sampled only specific population groups (for example, infants, institutionalised elderly populations) or only report $\mathrm{Zn}$ intakes ${ }^{(2)}$.

Studies that have assessed a broader range of healthy, community-dwelling adults in Australia have mostly reported $\mathrm{Zn}$ intakes only ${ }^{(3-7)}$, with few reporting serum $\mathrm{Zn}$ data ${ }^{(8,9)}$. As even the most recent of these Australian studies was reported a decade ago, they also pre-date the introduction of current procedures recommended by the International Zinc Nutrition Consultative Group (IZiNCG) for the assessment of $\mathrm{Zn}$ status; which include standardised collection procedures and age/sex/time of day-specific cut-off values for serum $\mathrm{Zn}^{(10)}$, making interpretation of the data difficult. Finding suitable biomarkers for $\mathrm{Zn}$ status in large study cohorts remains troublesome; various biomarkers have been investigated, such as leucocyte $\mathrm{Zn}^{(11)}$, lymphocyte ecto-5' nucleotidase $^{(12)}$ as well as hair and urinary $\mathrm{Zn}$. However, a 2009 systematic review suggests that serum $\mathrm{Zn}$, when collected in controlled conditions, remains as perhaps the most convenient and reliable biomarker for assessing $\mathrm{Zn}$ status in population studies ${ }^{(13)}$. Serum $\mathrm{Zn}$ is sensitive to acutephase responses, feeding state and time of day, and varies with sex and age. Collection systems are also vulnerable to contamination with exogenous $\mathrm{Zn}$ and so the methods outlined by IZiNCG are designed to control these various factors.

Abbreviations: AGP, $\alpha-1$ acid glycoprotein; EAR, estimated average requirement; IZiNCG, International Zinc Nutrition Consultative Group.

*Corresponding author: Dr J. M. Beckett, fax +61 363243995, email jbeckett@utas.edu.au 
In addition to $\mathrm{Zn}$ intake, other dietary factors, such as meat and in particular the phytate content of the diet, can influence the bioavailability of $\mathrm{Zn}$. Phytate has been observed to be a particular problem in developing countries in which diets are low in animal-based foods and rich in phytate-containing unrefined grains, cereals and legumes ${ }^{(14)}$. Although dietary fibre has also been thought to negatively affect $\mathrm{Zn}$ absorption it is likely that such a relationship was observed due to phytate generally being found in fibre-rich foods; research has shown that fibre in the absence of phytate has little influence on $\mathrm{Zn}$ absorption $^{(15)}$. Even mild $\mathrm{Zn}$ deficiencies may be associated with increased morbidity, involving alterations in immune function $^{(16)}$ and delayed wound healing ${ }^{(17)} ; \mathrm{Zn}$ insufficiency has been associated with neural tube defects ${ }^{(18)}$ and is considered by the WHO as a candidate for prenatal programming of chronic disease in later life ${ }^{(19)}$.

Tasmania has a history of suboptimal or marginal status in other micronutrients such as iodine $\mathrm{e}^{(20)}$ and $\mathrm{Se}^{(21,22)}$, but there is very little information about the status of other trace elements in the Tasmanian population. The population is ageing and has high rates of chronic disease ${ }^{(23)}$. Due to the lack of data relating to $\mathrm{Zn}$ status in Tasmanian populations, this cross-sectional study was undertaken to determine the $\mathrm{Zn}$ status of an adult population sample from northern Tasmania and identify any population groups that may be at risk of suboptimal status.

\section{Methods and materials}

\section{Study population}

This was a cross-sectional population study. The participants for the study were apparently healthy community-dwelling adults residing in the main population centres in north, northwest and northeastern Tasmania. Recruitment was by way of a mail-out to a random sample of adults taken from an extract of the Australian electoral roll provided by the Australian Electoral Commission. The study was conducted according to the guidelines laid down in the Declaration of Helsinki, and all procedures involving human subjects were approved by the Human Research Ethics Committee, Tasmania (reference no. H0009038). Written informed consent was obtained from all participants.

\section{Sample collection and preparation}

Participants completed questionnaires to provide demographic and anthropometric information. A semi-quantitative FFQ ${ }^{(24)}$ which uses Australian food content tables, was used to collect dietary data. The socio-economic status of participants was estimated by using the SEIFA (Socio-Economic Indexes for Areas) index for the area (ABS Collector District) in which each subject resided. The SEIFA index is derived from Australian Census variables related to advantage and disadvantage, including households with low or high income, unemployment rates and proportions of individuals with limited or higher education ${ }^{(25)}$. A lower SEIFA score in a Census district indicates that the district is relatively disadvantaged compared with one with a higher score.

Participants attended phlebotomy centres to provide a morning, non-fasting, venous blood sample, collected into trace element-free Vacutainer tubes without anticoagulant (Becton Dickinson). Following collection, blood samples were separated by refrigerated centrifugation for $15 \mathrm{~min}$ at $1335 \mathrm{~g}$. Samples of serum were stored at $-80^{\circ} \mathrm{C}$ until analysis. All laboratory glassware, consumables and storage vessels used during $\mathrm{Zn}$ analysis were acid washed $\left(1 \% \mathrm{HNO}_{3}\right)$ before use.

\section{Analytical methods}

Serum $\mathrm{Zn}$ concentrations were determined by flame atomic absorption spectrometry using a Spectra 880 spectrophotometer (Varian Inc.) and the method of Meret \& Henkin ${ }^{(26)}$. Analysis of Seronorm controls (Sero) with assayed Zn concentrations of 14.0 and $16.1 \mu \mathrm{mol} / 1$ gave means of 13.0 (CV $4.8 \%$; $n$ 38) and $17.8 \mu \mathrm{mol} / 1$ (CV $4.0 \% ; n$ 38). Intra-assay precision was $3.5 \%$ ( $n$ 13). Serum $\alpha-1$ acid glycoprotein (AGP) was determined by an immunoturbidimetric method on a Konelab 20XT autoanalyser (Thermo Fisher Scientific) using Dako anti-AGP antibody. Analysis of Dako controls with AGP concentrations of 0.58 and $1.52 \mathrm{~g} / 1$ gave means of $0.63(\mathrm{CV} 2.1 \% ; n$ 13) and $1.44 \mathrm{~g} / 1(\mathrm{CV} 1.8 \% ; n$ 13), respectively. Intra-assay precision was $2.2 \%(n$ 20).

\section{Statistical analysis}

Differences in $\mathrm{Zn}$ status within age and sex groups were estimated using general linear modelling (GLM) with robust standard error estimation (STATA version SE12; StataCorp LP). Post-estimation Holm's test analysis was used to adjust $P$ values for multiple comparisons ${ }^{(27)}$. Associations between serum $\mathrm{Zn}$ and $\mathrm{Zn}$ intake, monounsaturated fat intake, age, socio-economic status and BMI were estimated using GLM. Selection of variables for inclusion in a multivariate model was performed using stepwise regression from: $\mathrm{Zn}$ intake, fat, protein and carbohydrate intake, age, socio-economic status, BMI and sex. The validity of regression assumptions was tested by post hoc analysis to exclude significant heteroskedasticity and missing variable effects.

Sample serum Zn concentrations were compared with the accepted sex/age cut-off values of $10.7 \mu \mathrm{mol} / 1$ for men and $10 \cdot 1 \mu \mathrm{mol} / 1$ for women, as recommended by $\mathrm{IZiNCG}^{(10)}$. Most analyses used raw dietary intake data; however, as data were collected from a single time point, an adjusted estimate of the prevalence of low intakes was made, accounting for intra-individual variation, with an assumed $\mathrm{CV}$ of $25 \%$, as per IZiNCG's recommended methodology ${ }^{(28)}$.

As serum $\mathrm{Zn}$ is known to be reduced in subclinical infection or inflammation, serum AGP $>1.2 \mathrm{~g} / 1$ was used as an indicator of current infection/inflammation. Due to the variation in response from different age and sex subgroups in the study sample, a population estimate was made using data from the 2006 Australian Census for this region, weighted for age, sex and socio-economic status. 


\section{Results}

\section{Subject characteristics}

Subject characteristics are presented in Table 1. The study sample was comprised of 497 adults from northern Tasmania (191 men and 306 women) with a mean age of 57.4 (SD 12.3) years. Decadal age groups were 20-29 years ( $n$ 14), 30-39 years ( $n$ 36), 40-49 years $(n$ 76), 50-59 years ( $n$ 128), 60-69 years $(n$ 160), 70-79 years $(n$ 81) and 80-89 years $(n 2)$. Of the individuals who reported existing health conditions, the major conditions were hypertension $(25 \%)$ and arthritis (19\%); the most commonly reported medications used were anti-hypertensives $(24 \%)$, cholesterol-lowering drugs $(16 \%)$ and anticoagulants $(12 \%)$.

Mean contributions to total energy among the cohort for carbohydrate was $44 \%$, fats $34 \%$ (saturated $14 \%$; monounsaturated $12 \%$; polyunsaturated $5 \%$ and protein $19 \%$. Major food sources of energy were dairy product-based foods $23 \%$, cereal-based foods $22 \%$, meat fish and poultry $14 \%$ and fruit and vegetables $18 \%$. Mean dietary fibre was $26.7 \mathrm{~g} / \mathrm{d}$ in men, and $21.1 \mathrm{~g} / \mathrm{d}$ in women, less than the Australian adequate intake of $30 \mathrm{~g} / \mathrm{d}$ and $25 \mathrm{~g} / \mathrm{d}$, respectively. The FFQ used in the present study did not specifically assess phytate levels and Australian food tables do not contain information on phytate content. Tasmanians, however, consume a modern Western diet in which phytate-rich food such as unleavened breads are rare and unrefined grains and seeds are consumed in relatively low amounts.

\section{Dietary zinc intake}

Mean intakes of $\mathrm{Zn}$ were 12.6 (SD 4.4 ) $\mathrm{mg} / \mathrm{d}$ for men and 10.9 (SD 3.6$) \mathrm{mg} / \mathrm{d}$ for women. Overall, $26 \%$ of the study sample consumed less than the Australian/New Zealand estimated average requirement (EAR) for $\mathrm{Zn}$. Of the men, $52 \%$ consumed less than the EAR for adult males $(12 \mathrm{mg} / \mathrm{d})^{(29)}$. The proportion of men that consumed less than the EAR increased with age. The lowest proportion was observed in the 20-29 years age range (20\%); increasing to 36\% (30-39 years), $46 \%$ (40-49 years), $45 \%$ (50-59 years), $54 \%$ (60-69 years), $71 \%$ (70-79 years) and $100 \%$ in the $80-89$ years age range.
Of the women, $9 \%$ consumed less than the EAR for adult females of $6.5 \mathrm{mg} / \mathrm{d}$. A trend for increasing proportions of low intakes with age was not observed in women; no women in the youngest or oldest age range consumed less than the EAR and the greatest proportion of women to do so were aged 40-49 years (12\%). Similar proportions of low intakes were observed in the remaining age ranges: $30-$ 39 years, $8 \%$; 50-59 years, $10 \%$; 60-69 years, $8 \%$; 70-79 years, $8 \%$.

After adjusting for intra-individual variation (CV of $25 \%)^{(28)}$, it was estimated that approximately $42.3 \%$ of men and $5.4 \%$ of women had $\mathrm{Zn}$ intakes below the EAR.

The major food groups contributing to $\mathrm{Zn}$ intakes were meat, fish and poultry, cereal products, legumes and nuts, vegetables and dairy products. Meat, fish and poultry made a significantly higher contribution to $\mathrm{Zn}$ intakes in men than in women $(31.6 v .26 .3 \%$; $95 \%$ CI of difference 3.1 to $7 \cdot 2 ; P<0.001)$, while vegetables $(19.4 v .16 .8 \% ; 95 \%$ CI of difference 1.2 to $3 \cdot 9 ; P<0 \cdot 001)$, dairy products $(20 \cdot 1 v$. $16.3 \% ; 95 \%$ CI of difference $2 \cdot 2$ to $5 \cdot 5 ; P<0 \cdot 001)$ and fruit $(6.7$ v. $5.2 \% ; 95 \%$ CI of difference 0.8 to $2 \cdot 1 ; P<$ $0 \cdot 001)$ made greater contributions to $\mathrm{Zn}$ intakes for women.

Significantly higher vegetable consumption was observed in men older than 45 years compared with those younger than 45 years (359 v. $302 \mathrm{~g}$; $95 \%$ CI of difference 15 to 99; $P=0 \cdot 008$ ). This resulted in a significantly increased contribution to overall $\mathrm{Zn}$ intake from vegetables in men older than 45 years compared with younger men $(17.9 v .12 .2 \%$; $95 \%$ CI of difference 3.9 to $7 \cdot 4 ; P<0 \cdot 001)$. The consumption of meat $(132$ v. $150 \mathrm{~g} ; 95 \%$ CI of difference -2 to $39 ; P=0.07)$ and the proportion of $\mathrm{Zn}$ contributed by meat sources tended to be lower in the older men (31 v. $35 \%$; $95 \%$ CI of difference -0.8 to $7 \cdot 9 ; P=0 \cdot 11)$ but the differences did not reach statistical significance.

\section{Other associations with zinc status}

Selection of measured variables associated with serum $\mathrm{Zn}$ using stepwise regression (Table 2 ) revealed positive associations with dietary $\mathrm{Zn}$ intake $(P=0.036)$ and BMI $(P=0.015)$, while monounsaturated fat intake, age and socio-economic

Table 1. Characteristics of the study subjects (Mean values, standard deviations and ranges)

\begin{tabular}{|c|c|c|c|c|c|c|}
\hline & \multicolumn{3}{|c|}{ Male (n 191) } & \multicolumn{3}{|c|}{ Female ( $n$ 306) } \\
\hline & Mean & $\mathrm{SD}$ & Range & Mean & SD & Range \\
\hline Age (years) & 58.9 & $12 \cdot 2$ & 24-82 & $56 \cdot 5$ & $12 \cdot 2$ & $26-80$ \\
\hline BMI $\left(\mathrm{kg} / \mathrm{m}^{2}\right)$ & $27 \cdot 7$ & 4.6 & $18 \cdot 5-43 \cdot 8$ & $26 \cdot 5$ & $5 \cdot 2$ & $15 \cdot 9-46 \cdot 8$ \\
\hline Weight (kg) & $86 \cdot 2$ & $15 \cdot 1$ & $57 \cdot 0-155 \cdot 0$ & $70 \cdot 6$ & $14 \cdot 8$ & $46 \cdot 0-132 \cdot 0$ \\
\hline Height (cm) & $176 \cdot 6$ & 7.9 & $155 \cdot 0-198 \cdot 0$ & $163 \cdot 3$ & $7 \cdot 3$ & $144 \cdot 5-203 \cdot 0$ \\
\hline Dietary Zn (mg/d)* & $12 \cdot 6$ & 4.4 & 4.0-29.6 & 10.9 & 3.6 & $3.5-33.4$ \\
\hline Serum Zn $(\mu \mathrm{mol} / \mathrm{l})$ & $13 \cdot 0$ & 2.4 & $7 \cdot 5-24.5$ & $13 \cdot 0$ & 2.5 & $7 \cdot 6-23 \cdot 8$ \\
\hline \multicolumn{7}{|l|}{ Smoking $(n)$} \\
\hline Never & \multicolumn{3}{|c|}{96} & & \multicolumn{2}{|c|}{185} \\
\hline Previously & \multicolumn{3}{|c|}{84} & & \multicolumn{2}{|c|}{88} \\
\hline Current & \multicolumn{3}{|c|}{9} & & \multicolumn{2}{|c|}{30} \\
\hline Not known & \multicolumn{3}{|c|}{2} & & \multicolumn{2}{|c|}{3} \\
\hline
\end{tabular}

* Estimated average requirement: $12.0 \mathrm{mg} / \mathrm{d}$ for men; $6.5 \mathrm{mg} / \mathrm{d}$ for women ${ }^{(22)}$. 
Table 2. Multivariate analysis: association between mean serum zinc and variables selected by stepwise regression*

\begin{tabular}{lcccc}
\hline & Mean & $\beta$ & $95 \% \mathrm{Cl}$ & $P$ \\
\hline Constant $(\mu \mathrm{mol} / \mathrm{l}) \dagger$ & 13.0 & & $12 \cdot 8,13.2$ & \\
Dietary Zn $(\mathrm{mg} / \mathrm{d})$ & & 0.3 & $0.1,0.5$ & 0.036 \\
BMI $\left(\mathrm{kg} / \mathrm{m}^{2}\right)$ & & 0.3 & $0.1,0.6$ & 0.015 \\
Dietary monounsaturated fat $(\mathrm{g} / \mathrm{d})$ & & -0.4 & $-0.6,-0.1$ & 0.009 \\
Age (years) & & -0.3 & $-0.5,-0.1$ & 0.011 \\
SEIFA & & -0.3 & $-0.5,-0.1$ & 0.006
\end{tabular}

SEIFA, Socio-Economic Indexes for Areas.

* The effect of dietary $\mathrm{Zn}$ intake, BMl, dietary monounsaturated fat, age and socioeconomic status (SEIFA) (as standardised normal transformations) was estimated using general linear modelling. Variables were selected for this model from dietary Se intake, BMI, fat, protein and carbohydrate intake, age, sex and SEIFA, using stepwise regression.

† Constant is the overall mean serum Zn concentration.

$\ddagger$ Derived from Australian Census variables related to advantage and disadvantage. A lower SEIFA score for a given population area indicates it is relatively disadvantaged compared with one with a higher score.

status were negatively associated with serum $\mathrm{Zn}($ all $P<0 \cdot 02)$. There was no significant association between dietary fibre and serum $\mathrm{Zn}(P=0 \cdot 89)$.

\section{Serum zinc}

Mean serum Zn was 13.0 (sD 2.4) and 13.0 (sD 2.5) $\mu \mathrm{mol} / 1$ for men and women, respectively. Overall, serum $\mathrm{Zn}$ levels decreased with age in men, but not in women; this trend can be seen in Fig. 1(a) and (b). While $15 \%$ of all men had low serum $\mathrm{Zn}$, none aged $<40$ years had serum $\mathrm{Zn}$ below the IZiNCG cut-off $(10 \cdot 7 \mu \mathrm{mol} / \mathrm{l})^{(10)}$. The prevalence of low serum $\mathrm{Zn}$ in men varied in the older age ranges; in the 40 49 years range only $4 \%$ had serum $\mathrm{Zn}$ below the cut-off, but this increased to $19 \%$ (50-59 years) and $8 \%$ (60-69 years) and peaked at $31 \%$ in those aged 70-79 years.

Of the women, $7 \%$ had serum $\mathrm{Zn}$ below the IZiNCG cutoff $(10 \cdot 1 \mu \mathrm{mol} / \mathrm{l})^{(10)}$. Of the women aged $20-29$ years, $22 \%$ had low serum $\mathrm{Zn}$ and while the only subject aged 80-89 years also had a low serum $\mathrm{Zn}$ level, the proportion in other age ranges was $<10 \%$; 30-39 years $(8 \%), 40-49$ years $(8 \%)$, 50-59 years (6\%), 60-69 years $(4 \%)$ and $70-79$ years $(8 \%)$.

Of the participants, $3 \%(n$ 15) had serum AGP $>1.2 \mathrm{~g} / \mathrm{l}$, indicating current inflammation/infection. Serum $\mathrm{Zn}$ was not significantly different in those who had AGP values below compared with above this level $(12 \cdot 1 v .13 \cdot 1 \mu \mathrm{mol} / \mathrm{l}$; $95 \%$ CI of difference $-2 \cdot 3$ to $0 \cdot 3 ; P=0 \cdot 13)$. Of these subjects with elevated AGP only two had serum $\mathrm{Zn}$ below cut-off values, one male in the 50-59 years age range and one female in the 30-39 years age range.

In the adjusted population estimates (Table 3 and Fig. 1(c)), serum $\mathrm{Zn}$ concentrations and the prevalence of low $\mathrm{Zn}$ intakes and serum $\mathrm{Zn}$ levels below relevant cut-off values were not significantly different compared with the study sample $(P>0 \cdot 7)$.

\section{Discussion}

Micronutrient deficiency, including $\mathrm{Zn}$ deficiency, is a problem for a significant proportion of the world's population. Moreover, it appears that even the more commonly occurring
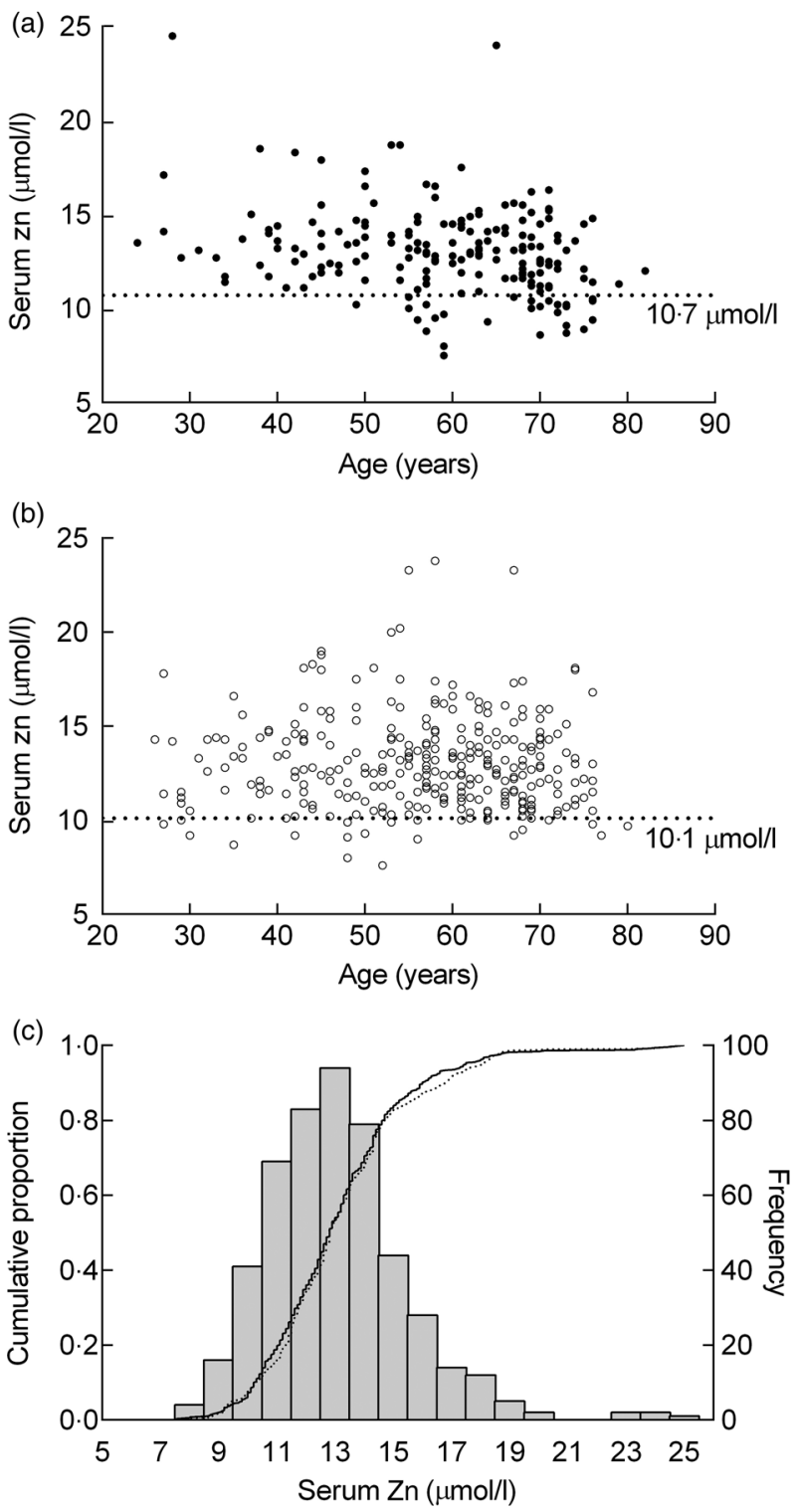

Fig. 1. Serum zinc concentrations of population samples. (a) Serum zinc concentrations of male ( $n$ 191) and (b) female ( $n$ 306) subjects compared with International Zinc Nutrition Consultative Group (IZiNCG) cut-off values. (c) Frequency distribution (histogram), and cumulative proportion (lines) of sample (-) and population (....) estimate of serum zinc in northern Tasmania, adjusted for age, sex and socio-economic status.

mild deficiency can increase morbidity ${ }^{(16,17,30)}$, but there is very little information on the $\mathrm{Zn}$ status in Australian populations. In fact, the present study appears to be only the second to date to report both dietary and biochemical data on $\mathrm{Zn}$ status from a representative population sample in Australia, and the only such study in Tasmanians. The major finding is the relatively high prevalence of low $\mathrm{Zn}$ status in older Tasmanian men. In the present study over half of the men consumed less than the EAR for $\mathrm{Zn}(12 \mathrm{mg})$, and the prevalence of low intakes increased with age, with nearly $75 \%$ of men over 70 years consuming inadequate $\mathrm{Zn}$. Even in an adjusted estimate of intakes using a CV of $25 \%$, approximately $42 \%$ of men reported low intakes. The prevalence of low serum $\mathrm{Zn}$ levels $(<10.7 \mu \mathrm{mol} / \mathrm{l})$ in older men was also high; 
Table 3. Estimates of population proportions with zinc intakes below the Australian/New Zealand estimated average requirement (EAR) ${ }^{\star}$ and with serum zinc below International Zinc Nutrition Consultative Group (IZiNCG) cut-offs $†$

\begin{tabular}{|c|c|c|c|c|c|c|c|}
\hline & Sample estimate & $95 \% \mathrm{Cl}$ & Population estimate & $95 \% \mathrm{Cl}$ & Risk ratioł & $95 \% \mathrm{Cl}$ & $P$ \\
\hline \multicolumn{8}{|l|}{ Zn intake } \\
\hline $\begin{array}{l}\text { Percentage }<\text { EAR } \\
\text { Serum } \mathrm{Zn}\end{array}$ & 26 & $0.22,0.30$ & 25 & $0.21,0.29$ & 0.96 & $0.78,1.19$ & 0.72 \\
\hline Percentage < cut-off & 9.9 & $0.07,0.13$ & 9.3 & $0.07,0.12$ & 0.94 & $0.64,1.38$ & 0.75 \\
\hline
\end{tabular}

* Estimated average requirement: $12.0 \mathrm{mg} / \mathrm{d}$ for men; $6.5 \mathrm{mg} / \mathrm{d}$ for women ${ }^{(22)}$.

† IZiNCG serum Zn sex/age cut-off values: $10.7 \mu \mathrm{mol} / \mathrm{l}$ for men; $10.1 \mu \mathrm{mol} / /$ for women ${ }^{(10)}$.

$\ddagger$ Risk ratio $(95 \% \mathrm{Cl}$ ) estimated by Poisson regression adjusted for age, sex and socio-economic status.

low serum $\mathrm{Zn}$ was not observed in men below 40 years, but occurred in $18 \%$ of men 50 years or older and $30 \%$ of men 70 years or older. It is suggested that the risk of $\mathrm{Zn}$ deficiency in a population is elevated and of public health concern if $>25 \%$ of individuals consume inadequate intakes, or if $>20$ $\%$ have serum $\mathrm{Zn}$ below the relevant age/sex cut-off ${ }^{(10)}$.

Serum $\mathrm{Zn}$ concentrations can be decreased as an acutephase response in inflammation and infection. Our assessment of serum AGP indicated that the prevalence of inflammation or infection in the population sample was low; this was not unexpected as participants had flexibility in when they could attend for phlebotomy and hence could delay providing blood samples if they were feeling unwell. Even if those with elevated AGP were excluded it would not change the interpretation of the study's results significantly; in fact it would slightly increase the proportion of both men and women with low serum Zn concentrations.

Our multivariate model indicated that the major influences on serum $\mathrm{Zn}$ status in this sample were dietary factors, BMI, age and socio-economic status. Interestingly, socioeconomic status was negatively associated with serum $\mathrm{Zn}$ status, but while higher socio-economic status may often be considered to result in an improved diet quality and potentially higher micronutrient status, it has, in previous European studies, been associated with a slightly lower $\mathrm{Zn}$ status ${ }^{(31)}$.

In the present study, there were varying response rates in different population subgroups; however, the lack of difference between the sample and population estimates adjusted for age, sex and socio-economic status (Table 3) suggests that the overall findings from the sample are representative of the northern Tasmanian population.

Previous Australian studies of dietary $\mathrm{Zn}$ in adults have reported low intakes ${ }^{(2,7)}$; however, many are studies of agedcare residents. Of those to assess free-living older adults, results are conflicting. In a study of South Australian residents (in 1989; $n$ 2195) aged $65+$ years, Horwath ${ }^{(7)}$ reported relatively low mean intakes of 10.3 and $9.7 \mathrm{mg} / \mathrm{d}$ in men and women, respectively. Baghurst \& $\operatorname{Record}^{(32)}$ (in 1987; n 331) also surveyed older South Australians (65-75 years) and reported somewhat higher median intakes of $12.0 \mathrm{mg} / \mathrm{d}$ in men and $10.9 \mathrm{mg} / \mathrm{d}$ in women, similar to the median intakes for individuals aged $65+$ years in the present study of $11.1 \mathrm{mg} / \mathrm{d}$ (men) and $11.0 \mathrm{mg} / \mathrm{d}$ (women).

Overall, mean intakes in men from the present study (12.6 $\mathrm{mg} / \mathrm{d}$ ) were lower compared with the only other published Tasmanian data $(13.5 \mathrm{mg} / \mathrm{d})$ from the 1995 National Nutrition Survey ${ }^{(5)}$ and other Australian reports by English et al. (1983 National Dietary Survey of Adults; $n$ 1974; $15 \cdot 1$ $\mathrm{mg} / \mathrm{d})^{(3)}$ and the 20th Australian Total Diet Survey (in 2003; $14 \mathrm{mg} / \mathrm{d})^{(4)}$. Intakes were similar, however, to the large national study reported by Baghurst et al. (in 1991; $n 806 ; 12.8 \mathrm{mg} / \mathrm{d})^{(9)}$.

Women in the present study also consumed a similar $\mathrm{Zn}$ intake $(10.9 \mathrm{mg} / \mathrm{d})$ to that estimated by Baghurst et al. (in 1991; $n$ 874; $11.2 \mathrm{mg} / \mathrm{d}$ ) ${ }^{(9)}$ and English et al. (in 1983; $n$ 2421; $10.5 \mathrm{mg} / \mathrm{d})^{(3)}$ but approximately $20 \%$ more than Tasmanian women in the 1995 National Nutrition Survey $(9.1 \mathrm{mg} / \mathrm{d})^{(5)}$ and $30 \%$ more than estimated in the 20th Australian Total Diet Survey (in 2003; $8.4 \mathrm{mg} / \mathrm{d}$ ) ${ }^{(4)}$. While the present study, like those by Horwath ${ }^{(7)}$ and Baghurst et al. ${ }^{(9)}$, utilised semi-quantitative FFQ for dietary estimates, methodological differences from many of the other previous studies make further comparisons inappropriate.

The study of Baghurst $e t a l{ }^{(9)}$ also determined serum $\mathrm{Zn}$ in a smaller sample of South Australian adults, reporting mean values of $15.1 \mu \mathrm{mol} / \mathrm{l}(n$ 90) and $14.1 \mu \mathrm{mol} / 1$ ( $n$ 111) for men and women, respectively. This study preceded the use of IZiNCG cut-off values ${ }^{(10)}$ for assessing the risk of $\mathrm{Zn}$ deficiency and hence did not calculate the proportions of individuals below the now-accepted cut-off values. The authors, however, did note a trend of decreasing serum $\mathrm{Zn}$ values with age, which, as in the present study, was most evident in men.

Comparable serum $\mathrm{Zn}$ data from healthy adult populations in other countries also appear limited. Similar serum Zn levels have been reported by one UK study ${ }^{(33)}$ in men $(13.9 \mu \mathrm{mol} / \mathrm{l}$; $n$ 95) and women $(13.3 \mu \mathrm{mol} / 1 ; n$ 94) with mean participant ages (45 and 49 years, respectively) lower than the present study. Serum Zn was also similar in a large Northern Ireland study $^{(34)}$ in both men $(13.2 \mu \mathrm{mol} / 1 ; n$ 1142) and women $(12.7 \mu \mathrm{mol} / \mathrm{l} ; n$ 1034); this study also reported a decline in $\mathrm{Zn}$ status with age among men, but not women.

A New Zealand study ${ }^{(35)}$ of elderly women (mean age 74.9 years; $n$ 102) reported a mean serum $\mathrm{Zn}$ of $12.4 \mu \mathrm{mol} / \mathrm{l}$. As noted by the authors, this concentration is relatively low compared with other published data, but it was still higher than women of a similar age in the present study $(11.6 \mu \mathrm{mol} / \mathrm{l})$.

A lower $\mathrm{Zn}$ status in older age groups is in accordance with a number of other studies ${ }^{(2,34-36)}$, and is a trend possibly due to a decrease in gastrointestinal absorption efficiency with age ${ }^{(37)}$, but changes in diet, as seen in the present study, as well as social and economic factors are also likely contributors. $\mathrm{Zn}$ is important for many broad biological processes. Recent research ${ }^{(36)}$ indicates an association between low $\mathrm{Zn}$ status and decreased immune function in the elderly and that low 
Zn status may be an important contributor to the immunosenescence observed in old age. $\mathrm{Zn}$ has also been associated with CVD, diabetes, neurodegenerative disease and cancer $^{(38)}$. Of the cancers, the development and progression of prostate cancer in particular appears to be associated with low Zn levels ${ }^{(39)}$, which in the context of this present study's findings, may be important.

The present results suggest that low Zn status may occur in a significant proportion of community-dwelling Tasmanians, and that there could be a relatively high prevalence of low $\mathrm{Zn}$ status in older males. Previous studies have shown that low $\mathrm{Zn}$ status is common in residential aged-care populations elsewhere in Australia ${ }^{(2)}$, and therefore the prevalence of low $\mathrm{Zn}$ status across the entire older Tasmanian population may be greater than suggested by the present study.

In the present study, the lack of agreement between the proportions of male subjects estimated to consume inadequate $\mathrm{Zn}$ and those with low serum $\mathrm{Zn}$ concentrations was probably due to a combination of factors, including limitations of the dietary data collection method (FFQ), intra-individual variability and under-reporting. The combined effect of these factors may explain why previous observational studies have generally failed to find significant associations between $\mathrm{Zn}$ intakes and serum $\mathrm{Zn}$ concentrations ${ }^{(40)}$. Established knowledge about the phytate content of Australian diets ${ }^{(41)}$, and the dietary information collected in the present study suggest that phytate intake is likely to have minimal influence on $\mathrm{Zn}$ status in this population.

The measurement of dietary intakes and serum $\mathrm{Zn}$ on multiple occasions for each participant would have strengthened the present study and should be included in future studies in this area. However, the findings of the study provide useful insight into groups that may be at risk of mild $\mathrm{Zn}$ deficiency in a population where no other data have been reported.

While the study sample had relatively low numbers of subjects in the extremes of the age range (youngest and oldest) there was reasonable representation of most age ranges and in particular those where the most significant findings were made (50+ years; $n$ 363). Further study of middle-aged and elderly Tasmanians, including both community-dwelling and aged-care residents, would be beneficial to confirm the prevalence of mild $\mathrm{Zn}$ deficiency in this population. Further investigation of the $\mathrm{Zn}$ status in the older populations of other states of Australia may also be warranted.

\section{Acknowledgements}

The present study was supported by a research grant from the Clifford Craig Medical Research Trust (Launceston, TAS, Australia). The Launceston General Hospital Pathology Department (Launceston, TAS, Australia), the NorthWest Pathology (Burnie, TAS, Australia), the Scottsdale Doctors Surgery (Scottsdale, TAS, Australia) and the Campbell Town Health and Community Centre (Campbell Town, TAS, Australia) assisted with blood collection, and the Royal Hobart Hospital Pathology Department (Hobart, TAS, Australia) assisted with specimen analysis. Dr Iain
Robertson, consultant biostatistician, assisted with the sample determination from the electoral roll and biostatistical analysis.

The authors thank Professor Graham Giles of the Cancer Epidemiology Centre of The Cancer Council of Victoria, for permission to use the Dietary Questionnaire for Epidemiological Studies ${ }^{(24)}$.

J. M. B. and M. J. B. designed the study; J. M. B. recruited the subjects, collected and analysed data and wrote the manuscript. M. J. B. discussed the data, corrected the manuscript and provided significant advice throughout.

Neither author had a conflict of interest.

\section{References}

1. Sanghvi T, Van Ameringen M, Baker J, et al. (2007) Vitamin and mineral deficiencies technical situation analysis: a report for the Ten Year Strategy for the Reduction of Vitamin and Mineral Deficiencies. Food Nutr Bull 28, S160-S219.

2. Gibson R \& Heath A-L (2011) Population groups at risk of zinc deficiency in Australia and New Zealand. Nutr Diet 68, 97-108.

3. English RM, Najman JM \& Bennett SA (1997) Dietary intake of Australian smokers and nonsmokers. Aust N Z J Public Health 21, 141-146.

4. Food Standards Australia New Zealand (2003) 20th Australian Total Diet Survey. Canberra: Food Standards Australia New Zealand.

5. McLennan W \& Podger A (1995) National Nutrition Survey: Nutrient Intakes and Physical Measurements. Canberra: Australian Bureau of Statistics.

6. McCarty CA, Nanjan MB \& Taylor HR (2002) Dietary intake of older Victorians. Nutr Diet 59, 12-17.

7. Horwath CC (1989) Dietary survey of a large random sample of elderly people: energy and nutrient intakes. Nutr Res 9, 479-492.

8. Ball MJ \& Ackland ML (2000) Zinc intake and status in Australian vegetarians. Br J Nutr 83, 27-33.

9. Baghurst KI, Dreosti IE, Syrette JA, et al. (1991) Zinc and magnesium status of Australian adults. Nutr Res 11, 23-32.

10. Brown KH, Rivera JA, Bhutta Z, et al. (2004) International Zinc Nutrition Consultative Group (IZiNCG) technical document \#1. Assessment of the risk of zinc deficiency in populations and options for its control. Food Nutr Bull 25, S99-S203.

11. Whitehouse RC, Prasad AS, Rabbani PI, et al. (1982) Zinc in plasma, neutrophils, lymphocytes, and erythrocytes as determined by flameless atomic absorption spectrophotometry. Clin Chem 28, 475-480.

12. Meftah S, Prasad AS, Lee DY, et al. (1991) Ecto 5' nucleotidase $\left(5^{\prime} \mathrm{NT}\right)$ as a sensitive indicator of human zinc deficiency. $J \mathrm{Lab}$ Clin Med 118, 309-316.

13. Lowe NM, Fekete K \& Decsi T (2009) Methods of assessment of zinc status in humans: a systematic review. Am J Clin Nutr 89, 2040S-2051S.

14. Schlemmer U, Frolich W, Prieto RM, et al. (2009) Phytate in foods and significance for humans: food sources, intake, processing, bioavailability, protective role and analysis. Mol Nutr Food Res 53, Suppl. 2, S330-S375.

15. Lonnerdal B (2000) Dietary factors influencing zinc absorption. J Nutr 130, 1378S-1383S.

16. Ibs KH \& Rink L (2003) Zinc-altered immune function. J Nutr 133, 1452S-1456S.

17. Lansdown ABG, Mirastschijski U, Stubbs N, et al. (2007) Zinc in wound healing: theoretical, experimental and clinical aspects. Wound Repair Regen 15, 2-16.

18. Velie EM, Block G, Shaw GM, et al. (1999) Maternal supplemental and dietary zinc intake and the occurrence of neural tube defects in California. Am J Epidemiol 150, 605-616.

19. Delisle H (2002) Programming of Chronic Disease by Impaired Fetal Nutrition. Evidence and Implications for Policy and Intervention Strategies. 
Geneva: WHO, Department of Nutrition for Health and Development.

20. Guttikonda K, Burgess JR, Hynes K, et al. (2002) Recurrent iodine deficiency in Tasmania, Australia: a salutary lesson in sustainable iodine prophylaxis and its monitoring. J Clin Endocrinol Metab 87, 2809-2815.

21. McGlashan ND, Cook SJ, Melrose W, et al. (1996) Maternal selenium levels and sudden infant death syndrome (SIDS). Aust N Z J Med 26, 677-682.

22. Beckett JM \& Ball MJ (2011) Marginal selenium status in northern Tasmania. Br J Nutr 106, 718-724.

23. Australian Bureau of Statistics (2006) National Health Survey: Summary of Results (2004-2005). Canberra: Australian Bureau of Statistics.

24. Giles GG \& Ireland PD (1996) Dietary Questionnaire for Epidemiological Studies (Version 2). Melbourne: The Cancer Council Victoria.

25. Australian Bureau of Statistics (2006) Socio-Economic Indexes for Areas (SEIFA): Technical Paper. Canberra: Australian Bureau of Statistics.

26. Meret S \& Henkin RI (1971) Simultaneous direct estimation by atomic absorption spectrophotometry of copper and zinc in serum, urine, and cerebrospinal fluid. Clin Chem 17, 369-373.

27. Aickin M \& Gensler H (1996) Adjusting for multiple testing when reporting research results: the Bonferroni vs Holm methods. Am J Public Health 86, 726-728.

28. International Zinc Nutrition Consultative Group (IZiNCG) (2007) Determining the Prevalence of Zinc Deficiency: Assessment of Dietary Zinc Intake. Technical Brief 3. Davis, CA: International Zinc Nutrition Consultative Group, c/o Program in International and Community Nutition, University of California.

29. National Health and Medical Research Council (2006) Nutrient Reference Values for Australia and New Zealand. Canberra: National Health and Medical Research Council.

30. MacDonald RS (2000) The role of zinc in growth and cell proliferation. J Nutr 130, 1500S-1508S.
31. Novaković R, Cavelaars A, Geelen A, et al. (2014) Socio-economic determinants of micronutrient intake and status in Europe: a systematic review. Public Health Nutr 17, 1031-1045.

32. Baghurst KI \& Record SJ (1987) The vitamin and mineral intake of a free-living young elderly Australian population in relation to total diet and supplementation practices. Hum Nutr Appl Nutr 41, 327-337.

33. Ghayour-Mobarhan M, Taylor A, New SA, et al. (2005) Determinants of serum copper, zinc and selenium in healthy subjects. Ann Clin Biochem 42, 364-375.

34. McMaster D, McCrum E, Patterson CC, et al. (1992) Serum copper and zinc in random samples of the population of Northern Ireland. Am J Clin Nutr 56, 440-446.

35. De Jong N, Gibson RS, Thomson CD, et al. (2001) Selenium and zinc status are suboptimal in a sample of older New Zealand women in a community-based study. J Nutr 131, 2677-2684.

36. Haase H \& Rink L (2009) The immune system and the impact of zinc during aging. Immun Ageing 6, 9.

37. Russell RM (1992) Changes in gastrointestinal function attributed to aging. Am J Clin Nutr 55, 1203S-1207S.

38. Chasapis CT, Loutsidou AC, Spiliopoulou CA, et al. (2012) Zinc and human health: an update. Arch Toxicol 86, 521-534.

39. Costello LC \& Franklin RB (2011) Zinc is decreased in prostate cancer: an established relationship of prostate cancer! J Biol Inorg Chem 16, 3-8.

40. Lowe NM, Medina MW, Stammers AL, et al. (2012) The relationship between zinc intake and serum/plasma zinc concentration in adults: a systematic review and dose-response meta-analysis by the EURRECA Network. Br J Nutr 108, 1962-1971.

41. International Zinc Nutrition Consultative Group (IZiNCG) (2004) International Zinc Nutrition Consultative Group (IZiNCG) technical document \#1. Assessment of the risk of zinc deficiency in populations and options for its control. Food Nutr Bull 25, S95-S203. 